\title{
Greater Granville Regeneration Strategy
}

\author{
Kay Tennant ${ }^{\mathrm{A}, \mathrm{B}}$ and Christine Newman ${ }^{\mathrm{A}}$ \\ ${ }^{\mathrm{A}}$ Centre for Population Health, Sydney West Area Health Service \\ ${ }^{\mathrm{B} C o r r e s p o n d i n g}$ author.Email: kay_tennant@wsahs.nsw.gov.au
}

\begin{abstract}
An urban regeneration health impact assessment (HIA) was conducted collaboratively with three major government agencies and the local community in 2005 and 2006 to identify health impacts of a major land use strategy outlined in the consultant's report for the Greater Granville Regeneration Plan - Stage 1 (Sydney: Hassall Pty Limited, 2005). Health impacts were identified and agreed recommendations were developed to ameliorate negative impacts, with a formal partnership agreement to progress implementation and monitoring. The Granville HIA has been influential in changing major policy initiatives of Parramatta City Council and the NSW Department of Housing, contributing to positive health outcomes for the Granville community.
\end{abstract}

The Greater Granville Regeneration Strategy health impact assessment (HIA) was based on the consultant's report for the Greater Granville Regeneration Plan Stage $1^{1}$ that was commissioned by Parramatta City Council and the NSW Department of Housing. The report identified ideas for improving Greater Granville grouped under five themes:

- Transport, traffic and parking, and pedestrian

- Business, industry and neighbourhood node

- Community facilities, medical services, childcare and schools

- Landscape, parks and recreation

- Housing and urban design.

The strategy included a review of public housing that would impact on over 1500 tenants including approximately 300 Aboriginal people. This potential impact raised both opportunities and concerns for the local community.

An urban regeneration strategy is a long-term plan for the social, physical, economic and environmental revitalisation of a defined area. ${ }^{2}$ There is a relatively undeveloped research base to demonstrate connections between urban regeneration and health outcomes. ${ }^{3}$ It is known that urban regeneration is a complex and multifaceted process that can have an impact on the wellbeing of communities through exemplification of housing availability and access to community facilities. ${ }^{3}$ Urban regeneration strategies also have the potential to target inequity through initiatives addressing wider social determinants of health such as housing, transport, employment and better access to fresh foods. ${ }^{4}$

\section{Methods}

The Granville HIA followed standard HIA methodology, ${ }^{5}$ incorporating a governance structure that utilised a community-based collaborative partnership framework. A Steering Group with representation from the Council, Department of Housing and the local community, encompassing Aboriginal and multicultural communities, was established to oversee the HIA. A small subgroup project team was responsible for conducting HIA-related tasks. The assessment was conducted in 2005 and 2006.

A shift in focus occurred during the HIA scoping phase due to a major stakeholder policy change driven by political concerns and subsequent media coverage relating to changes in housing densities. Original recommendation plans for feeding into future stages of the regeneration strategy were realigned to the major stakeholder policy drivers, including the Parramatta City Council Residential Development Strategy and the Department of Housing location-based regeneration methodologies. Consideration was also given to incorporating recommendations into Council's Local Environmental Plan due for completion in 2008.

Available qualitative and quantitative data assisted in identifying health impacts and formulating evidence, including:

- the consultant's report for Stage 1 of the Greater Granville Regeneration Plan

- community and stakeholder consultation reports ${ }^{6-11}$ based on large-scale community consultations conducted by external consultants (engaged by Parramatta City Council and NSW Department of Housing)

- consultation with HIA Steering Group based on the social determinants of health ${ }^{12}$

- consultation with the local Aboriginal community

- local demographic data and community profile

- literature and existing policy context review,

- local government health data.

A stakeholder focus group and a project team critical review process informed the HIA process evaluation. 


\section{Results}

The Granville HIA identified potential positive and negative health impacts as shown in Table 1.

Evaluation of the Granville HIA process highlighted some fundamental ingredients for successfully undertaking and completing the HIA. These included the importance of:

- Investment in partnership development through informal learning processes and training, generating a shared understanding of the potential worth of HIA before formally committing to the HIA process.

- Increasing awareness of HIA that facilitated the understanding of stakeholder organisations of how HIA could be incorporated into respective organisational policy and planning frameworks and encouraged non-health stakeholders to encompass a health dimension in community consultations before the formal HIA process.

- A shared understanding of organisational drivers of major HIA partners that ensured clarity of roles and delineated tangible benefits to the participating organisations. Understanding HIA and how it can be an influencing tool is only apparent when core policy and planning drivers are understood.
- Diverse stakeholder representation on the HIA Steering Group which significantly influenced the overall outcomes of the Granville HIA. In particular, representatives from Parramatta City Council such as the Deputy Lord Mayor, senior staff from the Department of Housing and representatives from the local Aboriginal community and local Multicultural Centre who provided links to their communities.

- Agreed resources for allowing commitment to conduct the Granville HIA. Each organisation (Sydney West Area Health Service, Parramatta City Council and NSW Department of Housing) nominated appropriate representatives to attend the HIA training and conduct the HIA. In addition, Sydney West Area Health Service allocated staff and time to lead the process and the NSW Department of Health committed two senior policy officers to assist in the HIA process and tasks.

Granville HIA provides a good example of the positive health influence that the HIA process can produce (Box 1). Future evaluation should consider the full extent of the HIA outcomes relative to the resource investment.

Table 1. Likely health impacts of the Greater Granville regeneration plan identified through the health impact assessment

\begin{tabular}{ll}
\hline HIA theme & Likely health impact \\
\hline $\begin{array}{l}\text { Transport, traffic, parking, } \\
\text { pedestrian, cycle }\end{array}$ & $\begin{array}{l}\text { Large positive impact if transport services and pedestrian connectivity is improved but } \\
\text { negative if improvement decreases access to services and pedestrian connectivity }\end{array}$ \\
$\begin{array}{l}\text { Business, industry, } \\
\text { neighbourhood node }\end{array}$ & $\begin{array}{l}\text { Medium positive impact if stated improvements implemented in nodes increase access to } \\
\text { fresh fruit and vegetables, multiple destinations for walking and cycling and local } \\
\text { employment opportunities }\end{array}$ \\
$\begin{array}{l}\text { Community facilities, } \\
\text { medical services, child care, } \\
\text { schools }\end{array}$ & $\begin{array}{l}\text { Large positive impact, in particular young people when community meeting places are more } \\
\text { available and accessible. Large negative impact on small number of children if housing } \\
\text { relocation prevents attendance at current school. Large negative impact on low SES } \\
\text { community if access to health services is reduced }\end{array}$ \\
$\begin{array}{l}\text { Landscape, parks, recreation, } \\
\text { access to Duck Creek }\end{array}$ & $\begin{array}{l}\text { Large positive impact as improvements indicated are activity friendly. Large positive impact for } \\
\text { Aboriginal community when Duck River restored }\end{array}$ \\
Urban design and housing & $\begin{array}{l}\text { Large positive impact for community if densities are increased. Large positive and negative } \\
\text { impacts on public housing tenants dependant on degree of control individuals have over } \\
\text { re-housing process; degree of access to medical priority housing; availability of range and } \\
\text { quality of residential accommodation }\end{array}$ \\
\hline
\end{tabular}

\section{Box 1. Outcomes of the Granville health impact assessment}

- The development of recommendations agreed by all stakeholders that underpin positive health outcomes

- Changes to new bus timetables based on community need and access to local destinations by NSW Department of Transport

- Discussions with NSW Department of Housing regarding feasibility of including HIA as a tool for broader policy application at the development phase of housing regeneration

- A formal partnership agreement with key stakeholders to progress the implementation and monitoring of the HIA recommendations

- Successfully influencing major policies drivers that will positively affect community health outcomes and

- The demonstration of HIA strength as a tool with a governance structure that brings community and large organisational stakeholders together on a level playing field. 


\section{Acknowledgements}

Denis McNamara (Parramatta City Council), Humair Ahmad (Dept of Housing), Maureen Owen (NSW Health), Robyn Thomas (NSW Health), Parramatta City Council, Dept of Housing Greater Western Sydney Division, Members of the Granville HIA Steering Committee, The general community and the Aboriginal community of Granville and South Granville, CHETRE, Professor Bill Randolph, Granville Youth and Recreation Centre Staff.

\section{References}

1. Greater Granville Regeneration Plan-Stage 1, Consultant's Report. Sydney: Hassall Pty Limited, 2005.

2. Metropolitan Borough of Wirral. Urban regeneration - the guiding principle for the UDP, 2007. Available at www.wirral.gov.uk/udp/urbanregen.asp, accessed 1 August 2007.

3. Mead E, Dodson J, Ellway C. Urban environments and health: identifying key relationships and policy imperatives. Brisbane: Griffith University, 2006.

4. Cave B, Curtis S, Aviles M, Coutts A. The potential health impacts of poor housing and housing change. In: Health impact assessment for regeneration projects, Vol. II selected evidence base. London: East London and the City Health Action Zone, 2001.

5. Quigley R, Cavanagh S, Harrison D, Taylor L. Clarifying health impact assessment, integrated impact assessment and health needs assessment. London: Health Development Agency, 2004.
6. Greater Granville Regeneration Plan - Through a child's eyes - "Week with a camera" at Granville. Prepared for Parramatta City Council and NSW Department of Housing. Sydney: Hassall Pty Ltd, 2004.

7. Greater Granville Regeneration Plan report on the stakeholders workshop. Prepared for Parramatta City Council and NSW Department of Housing. Nimbin, NSW: Sarkissian Associates Planners Pty Ltd, 2004.

8. Greater Granville Regeneration Plan report on the Greater Granville Expo. Prepared for Parramatta City Council and NSW Department of Housing. Nimbin, NSW: Sarkissian Associates Planners Pty Ltd, 2004.

9. Granville Aboriginal public housing tenants focus group consultation report. Prepared for Parramatta City Council and NSW Department of Housing. Parramatta: Parramatta City Council and NSW Department of Housing, 2005.

10. Mitar M. Granville youth consultation and workshop report. Parramatta: Parramatta City Council, 2004.

11. Tennant K, Newman C. Greater Granville Steering Committee workshop on the social determinants of health report. North Parramatta: SWAHS Centre for Population Health, 2005.

12. Marmot M, Wilkinson R, editors. The solid facts - social determinants of health. Copenhagen: World Health Organization, 2003. 